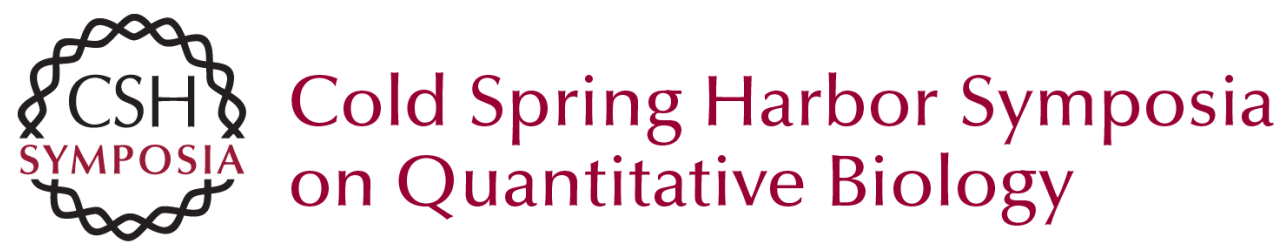

\title{
DNA-damage-induced Checkpoint Pathways in the Nematode Caenorhabditis elegans
}

\author{
E.R. HOFMANN, S. MILSTEIN and M.O. HENGARTNER \\ Cold Spring Harb Symp Quant Biol 2000 65: 467-474 \\ Access the most recent version at doi:10.1101/sqb.2000.65.467
}

References This article cites 53 articles, 17 of which can be accessed free at: http://symposium.cshlp.org/content/65/467.refs.html

Article cited in:

http://symposium.cshlp.org/content/65/467\#related-urls

Email alerting Receive free email alerts when new articles cite this article - sign up in the box at the service

To subscribe to Cold Spring Harbor Symposia on Quantitative Biology go to:

http://symposium.cshlp.org/subscriptions 


\title{
DNA-damage-induced Checkpoint Pathways in the Nematode Caenorhabditis elegans
}

\author{
E.R. Hofmann, S. Milstein, And M.O. Hengartner \\ Cold Spring Harbor Laboratory, Cold Spring Harbor, New York 11724
}

Genomic instability is believed to be an enabling characteristic of cancer (Hanahan and Weinberg 2000). Therefore, it is not surprising that sophisticated mechanisms exist to maintain the integrity of the genome. Damage to DNA triggers checkpoint controls that result in cell cycle arrest and repair of the lesion (Nurse 1997, 2000; Weinert 1998). In multicellular organisms, when DNA damage is extensive, these potentially harmful cells are eliminated by apoptosis (Enoch and Norbury 1995; Evan and Littlewood 1998). Defects in communications between DNA damage and the apoptotic program leads to the survival of cells with unstable genomes vulnerable to oncogene activation, ultimately leading to tumor development (Morgan and Kastan 1997; Orr-Weaver and Weinberg 1998; Hanahan and Weinberg 2000). Genetic work in yeast has greatly improved our understanding of the molecular mechanisms of DNA-damage-induced checkpoint arrest and repair. On the other hand, DNAdamage-induced apoptosis cannot be studied in yeasts, as the apoptotic program is missing in both Saccharomyces cerevisiae and Schizosaccharomyces pombe (Fraser and James 1998).

Studies on apoptotic responses to DNA damage in mammalian systems have focused mainly on p53 and ATM (ataxia-telangiectasia, mutated) (Morgan and Kas$\tan$ 1997). However, it is unclear how these molecules mediate cell death in response to DNA damage. Furthermore, it has become evident that $\mathrm{p} 53$-independent pathways exist that can also activate the apoptotic program in response to DNA damage (Clarke et al. 1993; Strasser et al. 1994).

The availability of a suitable genetic model system might be very useful to dissect these various pathways and identify their components. Although the nematode Caenorhabditis elegans has long been of great value in elucidating the apoptotic pathway, it has not been utilized to its full potential to study the cell cycle or DNA repair (Wood 1988; Riddle et al. 1997). Here, we report our initial efforts to utilize the power of $C$. elegans genetics to try to understand the link between DNA damage, cell cycle arrest, and apoptosis.

\section{CELL DEATH IN C. ELEGANS}

The genetics of apoptosis and its primary components have been defined largely by studies done in the nematode C. elegans (Metzstein et al. 1998; Horvitz 1999). More than 16 genes in $C$. elegans have been identified that function in cell death. The activity of three of these genes, ced-3 (cell death abnormal), ced-4, and egl-1 (egglaying abnormal), are required for all developmental cell deaths, whereas a fourth gene, ced-9, is required to protect surviving cells from apoptosis (Ellis and Horvitz 1986; Hengartner et al. 1992; Conradt and Horvitz 1998). Several structural and functional homologs of the C. elegans proteins have been identified in mammals. For example, CED-3 is homologous to the family of cysteine proteases known as caspases, and CED-4 is the nematode equivalent of the adapter protein Apaf-1 (Yuan et al. 1993; Zou et al. 1997). CED-9 is a member of the Bcl-2 family of cell death regulators, and the Bcl-2 homology3 (BH3) domain protein EGL-1 is similar to the proapoptotic proteins Bad, Bik, and Bid (Hengartner and Horvitz 1994; Conradt and Horvitz 1998).

Biochemical studies suggest that the key event that initiates apoptosis in C. elegans is the processing of CED-3 from its inactive zymogen form into the active caspase (Xue et al. 1996; Chinnaiyan et al. 1997). Autocatalytic activation of CED-3 requires association of the zymogen with oligomerized CED-4 (Yang et al. 1998). In cells fated to survive, CED-4 is bound to and sequestered by CED-9, thereby preventing oligomerization and CED-3 activation. The CED-9/CED-4 interaction is stable, but can be disrupted in cells fated to die (Chen et al. 2000). During development, dissociation of CED-4 from CED-9 is induced by binding of EGL-1 to CED-9 (Conradt and Horvitz 1998; del Peso et al. 2000).

Several of the protein-protein interactions observed in C. elegans are also conserved in mammals. First, activation of caspase-9 (CED-3 homolog) requires interaction with oligomerized Apaf-1 (CED-4 homolog) (Srinivasula et al. 1998). Second, binding of $\mathrm{BH} 3$ domain proteins (EGL-1 equivalents) to Bcl-2 or Bcl-xL (CED-9 homologs) inhibits the prosurvival function of these proteins (Oltvai et al. 1993; Kiefer et al. 1995; Antonsson et al. 1997). Thus, much of the death pathway is conserved between nematodes and mammals, both at the genetic and molecular levels, and general principles learned in worms can often be applied to humans.

\section{THE C. ELEGANS GERM LINE}

The C. elegans hermaphrodite gonad consists of two U-shaped tubes, which are joined by a common uterus (Fig. 1) (Schedl 1997). All of the mitotic and early meiotic germ cells are in a syncytium, partially enclosed by a plasma membrane, but joined together by a common cytoplasmic core (the rachis). The distal-most end of each 
tube is capped by a somatic cell called the distal tip cell (DTC), which interacts with the neighboring germ cells to maintain them in mitosis via a Notch-Delta, receptorligand interaction. As germ cells move outside the zone of influence of the DTC, they stop dividing and enter meiosis. Meiotic cells transiently arrest in pachytene of meiosis I until they approach the bend of the tube. By this time, oogenesis can be seen to occur as cells begin importing yolk and become considerably larger, before finally pinching off from the syncytium. Mature oocytes arrest again in diakinesis of meiosis I, where they will remain until fertilization.

Under ordinary growth conditions, approximately half of all female germ cells are doomed to die by programmed cell death (Gumienny et al. 1999). These "physiological" germ cell deaths are dependent on ced-3 and ced-4, since loss-of-function alleles of these genes block germ cell death. However, regulation of physiological germ cell death appears to be independent of egl-1. Therefore, it is likely that multiple pathways upstream of the basic apoptosis machinery regulate cell death in C. elegans.

Although germ cell death appears to be stochastic in nature, levels of cell death increase with the age of the worm, suggesting that the process can be influenced by extrinsic factors. Germ cell apoptosis is restricted to a region at or near the bend in the gonad, where germ cells exit pachytene (Fig. 1). Apoptosis is never seen in hermaphrodites undergoing spermatogenesis, nor in the male germ line. This may suggest that apoptosis has a role in oogenesis that is absent in spermatogenesis, possibly as a final checkpoint to make sure that oogenesis is occurring properly or to eliminate excessive cells, as the number of oocytes is physically limited by space (Gumienny et al. 1999).

\section{DNA DAMAGE RESPONSES IN THE $C$. ELEGANS GERM LINE}

In addition to cell deaths that occur naturally during oogenesis, germ cells can undergo apoptosis in response to genotoxic agents, such as $\gamma$-rays of the chemical mutagen $N$-ethyl- $N$-nitrosourea (ENU) (Gartner et al. 2000). This response appears to be dependent on the core apoptotic machinery, since the germ line of animals homozygous for the loss-of-function (lf) alleles ced-3(n717) or ced-4(n1162) show no cell death. In contrast to physiological germ cell death, DNA-damage-induced cell death is blocked by the ced-9 gain-of-function mutation $(n 1950)$, and it is reduced but not abolished in egl1(n3082lf). These observations suggest that egl-1 participates in, but is not essential for, DNA-damage-induced cell death.

In addition to increased germ cell death, genotoxic agents also induce a second response in germ cells: Following DNA damage, a transient arrest in cell proliferation can be seen in the mitotic compartment of the germ line. This response is not affected by ced-3(lf) mutants and, thus, can be separated genetically from DNA-damaged-induced cell death. In contrast to apoptosis, cell cycle arrest is seen only in the mitotic region, and occurs in both the hermaphrodite and male germ lines (Fig. 2). The spatial and genetic separation of cell cycle arrest and apoptosis in the germ line make it straightforward to study the two processes independently, as well as allowing the link between the two to be examined.

\section{MUTANTS OF DNA DAMAGE RESPONSES IN C. ELEGANS}

The results discussed above suggest that $C$. elegans possesses gene products that detect DNA damage and transmit this signal to the apoptotic machinery. Indeed, after screening through previously identified mutants with various defects in radiation responses and chromosomal maintenance, three mutations - rad-5(mn159), dam-1(op241), and mrt-2(e2663)-were identified that abrogate DNA-damage-induced cell cycle arrest and apoptosis (Gartner et al. 2000). These mutations do not affect developmental somatic cell death or physiological germ cell death. Consistent with what is observed in

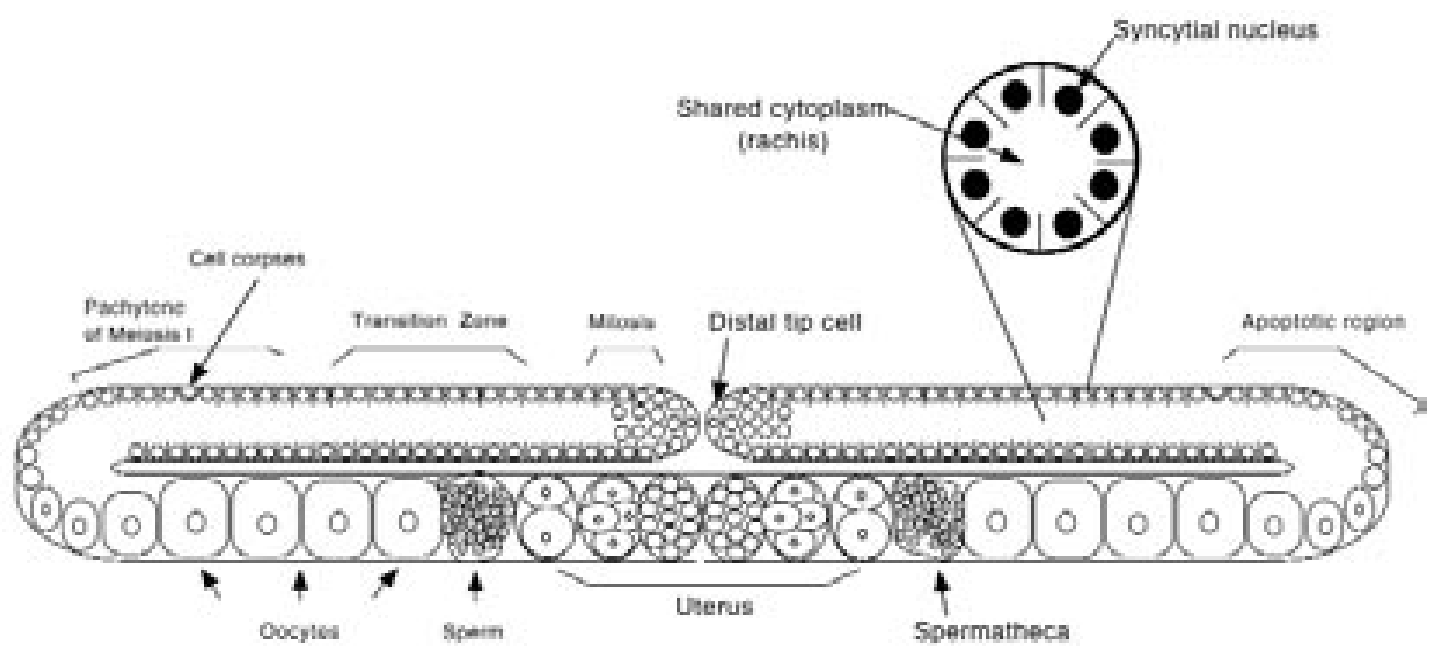

Figure 1. Diagram of the adult hermaphrodite gonad. 


\section{Wildtype Males}
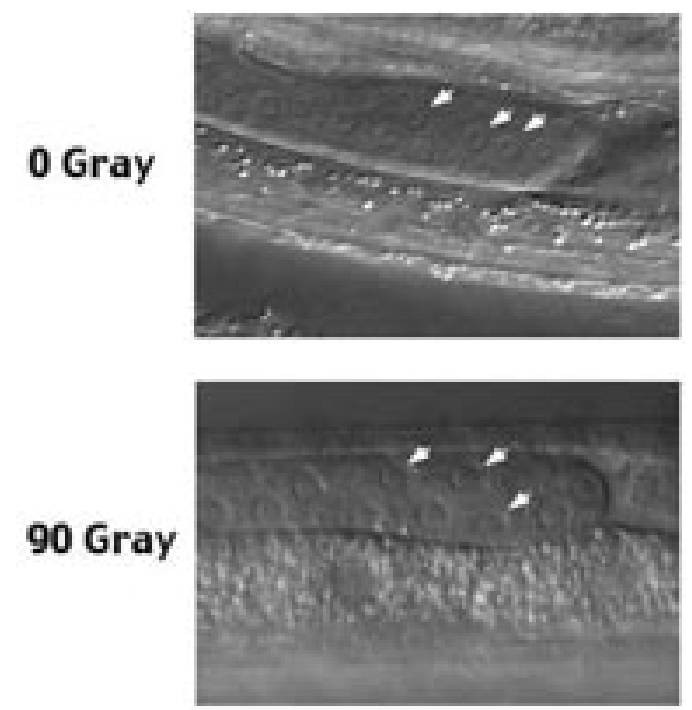

Figure 2. Genotoxic induction of cell cycle arrest of mitotic germ cells in the male gonad. Note increase in size of mitotic germ cells (arrows) exposed to ionizing radiation. Adult N2 males were photographed $8 \mathrm{hr}$ after being exposed to $90 \mathrm{~Gy}$ of $\gamma$-irradiation.

checkpoint gene mutants in yeast and mammals, all three mutants show an increase in genomic instability and reduced survival following DNA damage (Gartner et al. 2000). Taken together, these observations suggested that the mutations that we identified likely identify three checkpoint genes that function specifically in response to DNA damage.

Indeed, molecular characterization of $m r t-2$ revealed that this gene encodes a homolog of the $S$. pombe checkpoint gene Radl (Ahmed and Hodgkin 2000), demonstrating for the first time that Rad1 homologs are involved in DNA-damage-induced apoptosis. These results establish the existence of a genetic pathway in C. elegans that detects DNA damage and activates cell cycle arrest in a manner analogous to yeast. Furthermore, the same pathway activates the apoptotic response in C. elegans and, we predict, in humans. Therefore, further genetic analysis of this pathway should improve our understanding of DNA damage responses in humans.

\section{CELL CYCLE ARREST}

As mentioned above, genotoxic agents induce a proliferation arrest of mitotic germ cells at the distal end of the gonad. This arrest is characterized by a dramatic reduction of germ cell numbers in the mitotic compartment and an increase in the size of the germ nuclei. This increase in nuclear size is likely the result of continued import of nuclear components. Thus, DNA damage appears to cause cell cycle arrest, but not growth arrest. In contrast to germ cell apoptosis, proliferation arrest is not restricted to adult hermaphrodites. Males exposed to $\gamma$-irradiation also ex- hibit a transient cell division arrest in the mitotic compartment of the germ line (Fig. 2). Germ cell arrest can also be observed throughout larval hermaphrodite development (Fig. 3).

The exact phase of the cell cycle in which germ cells arrest following DNA damage has not been determined. In yeast, DNA damage induces $\mathrm{a}_{2} / \mathrm{M}$ arrest. Therefore, it is conceivable the same is true for nematodes. However, more work will be required to conclusively address this point.

The three mutants-mrt-2(e2663), rad-5(mn159), and dam-1(op241)—defective in DNA-damage-induced apoptosis also fail to undergo cell cycle arrest when exposed to ionizing radiation (Gartner et al. 2000). Thus, all three genes function in a common, evolutionarily conserved checkpoint pathway that mediates both cell cycle arrest and apoptosis in response to DNA damage. A similar situation exists in mammals, where genes such as p53 mediate both cell cycle arrest and apoptosis following DNA damage (Rich et al. 2000).

\section{CHECKPOINT RESPONSES DURING POSTEMBRYONIC DEVELOPMENT}

Development of the gonad occurs postembryonically, from the L1 through the L4 larval stages (Kimble and White 1981; Schedl 1997). At the time of hatching, the primordial gonad contains four cells named Z1, Z2, Z3, and $Z 4$. In the hermaphrodite, the two somatic precursor cells, Z1 and Z4, divide by an essentially invariant pattern to generate 143 somatic gonad cells, which will form the uterus, spermatheca, and syncytial sheath cells that surround the developing germ cells. Slightly different patterns of cell division will give rise to the vas deferens and seminal vesicles in males. Z2 and Z3 are the germ line precursors, and give rise to all germ cells. Unlike the invariant cell lineages that give rise to the somatic gonad, $\mathrm{Z} 2$ and $\mathrm{Z} 3$ divisions are generally variable and continuous in both sexes. Mitosis in the somatic and germ line precursor cells begins about midway through the L1 stage and gives rise to approximately 12 cells by the L1/ L2 molt.

Exposure of early larvae to $\gamma$-irradiation has a profound effect on gonadal development. Wild-type hermaphrodites exposed to 120 Gray of $\gamma$-irradiation 8 hours after hatching showed not only the typical increase in germ cell size described above, but also a dramatic reduction in the total number of cells (Fig. 3). Whereas nonirradiated worms have at least 12 cells in the developing gonad, the gonads of worms exposed to 120 Gray contained on average only 4 cells (Fig. 3). These observations suggest that the initial Z1 and Z4 somatic divisions were arrested as well as the germ cell divisions. This arrest appears to be regulated by the same pathway as the germ cell arrest since dam-1(op241) mutants fail to arrest properly (Fig. 3 ). Examination of wild-type larvae 36 hours after irradiation revealed a significant retardation of gonad development compared to nonirradiated worms, suggesting that irradiated germ cells eventually repair their DNA or habituate to the presence of damage. However, the gonadal 
A
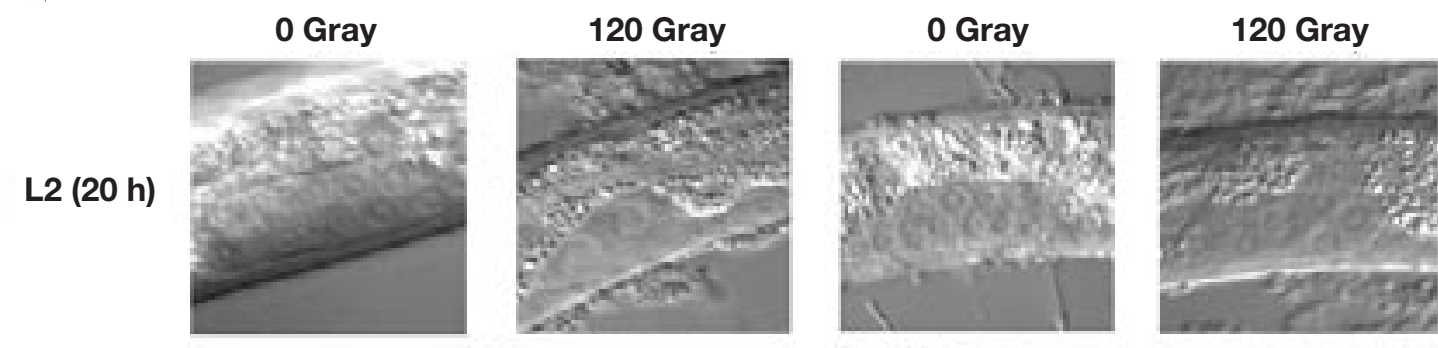

L3 (32 h)
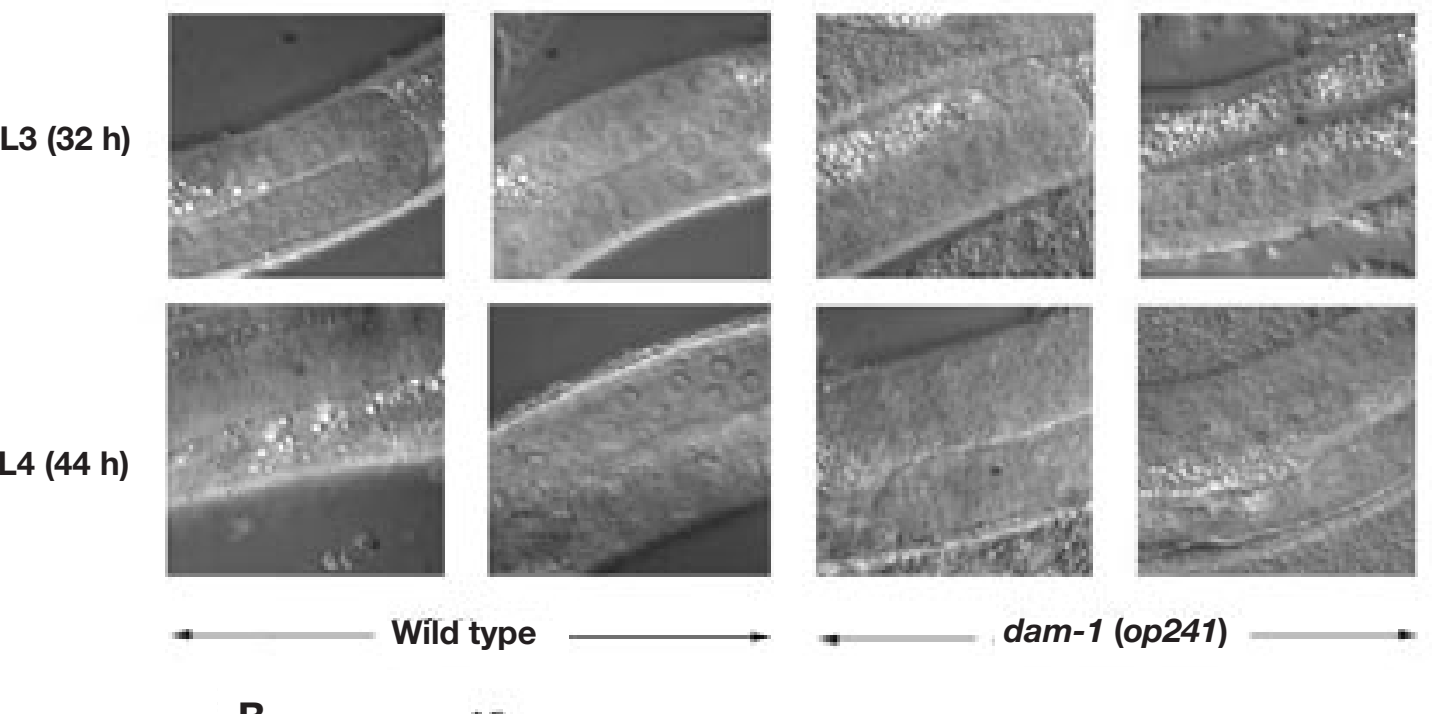

dam-1 (op241)

B

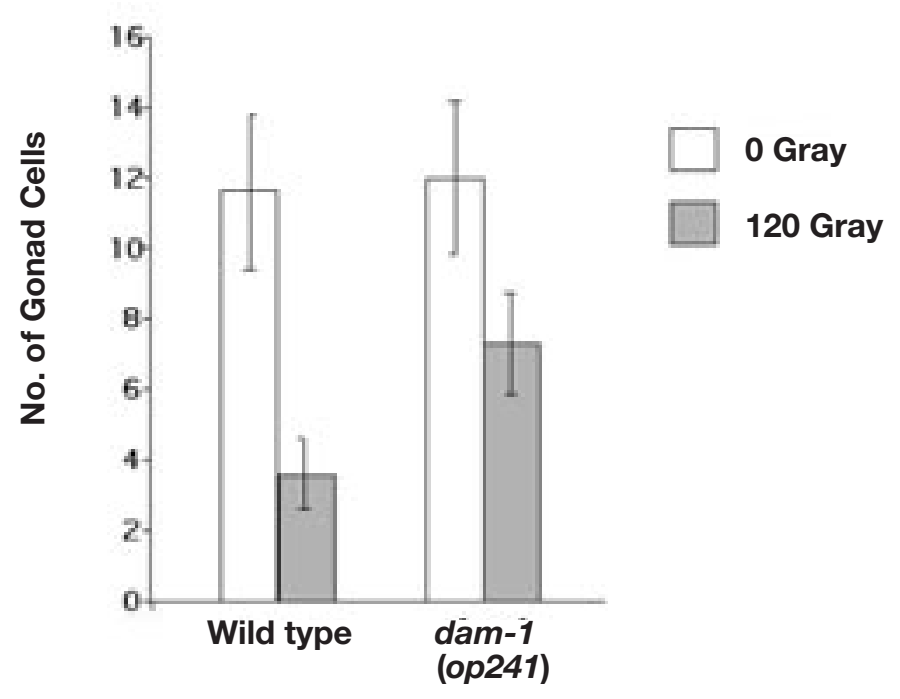

Figure 3. Genotoxic induction of cell cycle arrest in somatic gonadal cells and germ cells of hermaphrodite larvae. $(A)$ Synchronized hermaphrodite larvae were exposed to indicated doses of $\gamma$-irradiation $12 \mathrm{hr}$ prior to indicated times of observation (hr posthatching). $(B)$ Synchronized worms exposed to indicated doses of $\gamma$-irradiation $8 \mathrm{hr}$ posthatching, and total number of gonad cells were counted under Nomarski optics. Results are mean $\pm \operatorname{SEM}, n=10$.

developmental program never fully recovers and remains behind schedule, as the rest of larval development continues, oblivious to the stunted and/or delayed gonadal development.

DNA damage also affects other postembryonic cell divisions. For example, irradiated worms showed kinked, slowed locomotion, a phenotype usually associated with defects in neuromuscular function. Of particular interest are the divisions of the $\mathrm{P}$ cells in the late $\mathrm{L} 1$ larval ventral nerve cord. These 12 neuroblasts divide to generate several dozen new motor neurons, which are required for proper locomotion in older larvae and adults. In ncc-1 mutants, these neuroblasts fail to divide, resulting in a strong uncoordinated locomotion phenotype (Boxem et 
Table 1. Putative C. elegans Homologs of Human and Yeast Genes Indicated in Genomic Stability

\begin{tabular}{|c|c|c|c|c|c|c|}
\hline \multicolumn{4}{|c|}{ Species } & \multicolumn{2}{|c|}{ P. value ${ }^{\mathrm{a}}$; C. elegans vs. } & \multirow[b]{2}{*}{ Function/Similarity } \\
\hline S. pombe & S. cerevisiae & humans & C. elegans & S. pombe & humans & \\
\hline$\overline{\mathrm{Rad} 3}$ & $\mathrm{Mec} 1$ & ATR & $\mathrm{T} 06 \mathrm{E} 4.3^{\mathrm{b}}$ & $1 \mathrm{e}-45$ & $4 \mathrm{e}-66$ & PI3K-like \\
\hline Tel1 & Tel1 & ATM & Y48G1BL.f & $1 e-46$ & $5 e-58$ & PI3K-like \\
\hline Rad1 & $\operatorname{Rad} 17$ & Rad1 & MRT $-2^{\mathrm{C}} / \mathrm{HPR}-1^{\mathrm{d}}$ & $7 e-8$ & $2 \mathrm{e}-22$ & exonuclease \\
\hline Rad9 & Ded1 & hRad9 & Y39A1A & $3 e-17$ & $6 e-15$ & PCNA-like \\
\hline $\operatorname{Rad} 17$ & $\operatorname{Rad} 24$ & hRad17 & HPR $-17^{\mathrm{d}}$ & 0.33 & $2 \mathrm{e}-23$ & similar to RFC \\
\hline Hus1 & - & hHus1 & H26D21.1 & 0.011 & $4 e-22$ & PCNA-like \\
\hline Chk1 & - & hChk1 & Y39H10A.a & $1 e-41$ & $2 \mathrm{e}-70$ & serine/threonine kinase \\
\hline Cds1 & $\operatorname{Rad} 53$ & hChk2 & Y60A3A.12 & $1 \mathrm{e}-30$ & $3 e-57$ & serine/threonine kinase \\
\hline Cut5 & Dpb11 & - & $\mathrm{T} 13 \mathrm{~F} 2 / 3 \mathrm{a} / \mathrm{b}$ & $2 e-3$ & $6 e-40$ & XRCC1-like repeats \\
\hline $\mathrm{Crb} 2$ & $\operatorname{Rad} 9$ & p53BP & $\mathrm{T} 05 \mathrm{~F} 1.6 \mathrm{a} / \mathrm{b}$ & $8 e-4$ & $5 e-17$ & BRCT domain \\
\hline Rad51 & $\operatorname{Rad} 51$ & Rad51 & RAD $-51^{\mathrm{e}}$ & $1 e-108$ & $1 e-114$ & similar to $\operatorname{Rec} A$ \\
\hline - & - & BRCA1 & C36A4.8 & - & $3 e-10$ & Fam. breast/ovarian cancer \\
\hline Rhp54 & Rad54 & XNP & $X N P-1^{f}$ & $2 e-37$ & $6 e-90$ & ATR-X syndrome/helicase \\
\hline- & - & BLM & T04A11.6 & - & $1 e-120$ & Bloom's syndrome \\
\hline
\end{tabular}

Best hits were determined based on homology as determined by BLASTP.

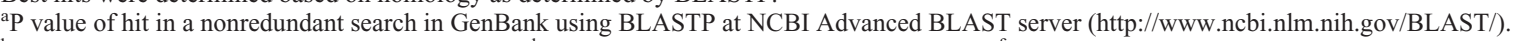

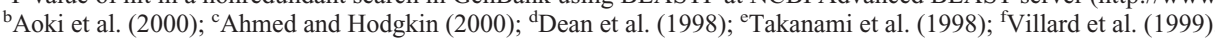

al. 1999). Since irradiated worms are not as strongly uncoordinated, most of these divisions probably are completed. More detailed analyses will be required to determine the exact extent of cell division defects in the ventral cord following DNA damage.

\section{RECOMBINATION}

Double-strand breaks occur not only when DNA is damaged, but also as a part of normal meiotic recombination. These double-strand breaks are generated by an endonuclease, encoded in yeast by the SPO11 gene (Roeder 1997). Repair of the double-strand breaks is initiated via strand invasion onto the homologous chromosome and concluded via resolution of the resulting Holliday junction. Strand invasion requires the product of the RAD51 gene, a member of the recA superfamily of single-strandbinding proteins. Inactivation of the nematode $\mathrm{rad}-51$ via RNA interference (RNAi) resulted in a drastic increase in germ cell apoptosis (Gartner et al. 2000). This increased germ cell death was due to unresolved double-strand breaks, as mutational inactivation of the gene spo-11, the enzyme responsible for the generation of double-strand breaks, caused no increased germ cell death. More importantly, the spo-11 mutation also suppressed the increased death caused by loss of RAD-51 function.

Several $C$. elegans mutants that have an increased rate of transposition have been identified (Ketting et al. 1999). One of the affected genes, mut-7, has recently been cloned and shown to encode a member of the RNase D family. Increased germ cell death can also be observed in these strains, possibly due to an increase in double-strand breaks (A. Gartner et al., unpubl.).

\section{CONSERVATION OF THE CHECKPOINT PATHWAY IN C. ELEGANS}

Since completion of the genomic sequence of $C$. elegans, researchers have been able to study gene function at the genomic level. A wealth of information can be obtained by analyzing the conservation of known genes for particular pathways. This is also true for the study of the known pathways in yeast and mammals that regulate responses to DNA damage. In $S$. pombe, the DNA damage sensory network consists of a complex of at least four proteins including the proliferating cell nuclear antigen (PCNA)-like proteins Rad1, Rad9, and Hus1, as well as Rad17, which is similar to replication factor C (Rhind and Russell 1998; Weinert 1998; O’Connell et al. 2000). In addition to the Rad1 homolog, mrt-2, C. elegans has homologs to the rest of the members of this complex (Table 1) (Dean et al. 1998). Regulation of this complex in $S$. pombe is mediated by the protein kinase Rad3, which has homology with the phosphatidylinositol 3-kinase (PI3K) ATR (ATM-related) in mammals. A second PI3K in $S$. pombe, Tel1, is not important for checkpoint function; however, the mammalian homolog ATM has an important role in checkpoint responses to ionizing radiation. RNAi of a C. elegans ATM homolog resulted in high embryonic lethality, high incidence of males due to X chromosome nondisjunction, and occasional aneuploidy of oocyte chromosomes (Aoki et al. 2000). C. elegans has multiple ATM and ATR candidates, although it has yet to be determined if they have a conserved function. Interestingly, $\operatorname{Rad} 26$, a protein that complexes with $\operatorname{Rad} 3$ in $S$. pombe, is weakly conserved in C. elegans. Rad26 homologs are not structurally conserved in higher organisms (O'Connell et al. 2000).

As with yeast and mammals, C. elegans possesses homologs to the two downstream kinases, Chk1 and Cds1 (hChk2), which are targets of the Rad3-like kinases (Table 1). It has yet to be determined if these kinases are important for regulation of separate types of damage as is the case in mammals. In $S$. pombe, the Cut5 gene product contains a BRCT domain termed for its similarity to the carboxyl terminus of the protein encoded by the human breast and ovarian cancer susceptibility gene (BRCA1). Another yeast protein, Crb2, also contains a BRCT domain and may interact with Cut5 (Saka et al. 1997). The checkpoint role of these proteins is still ambiguous; however, Crb2 is phosphorylated in response to DNA damage (Edwards et al. 1999). Multiple candidate genes exist in 
C. elegans with BRCT-like domains. Members of the Cdc25 phosphatase, Rad24 and Wee1 kinase, are also conserved. Thus, checkpoint control of cell cycle progression could be regulated in $C$. elegans in a manner similar to that in mammals and yeast. Recently, a weak homolog of p53 members, cep-1, has been identified that also appears to be important for DNA-damage-induced apoptosis in the germ line (W.B. Derry et al., pers. comm.). In the absence of cep-1, apoptosis does not occur following irradiation, although there is an increased basal level of apoptosis, suggesting that this p53 homolog may function in multiple ways in the worm germ line. In addition, a deletion mutant of this gene undergoes normal cell cycle arrest following irradiation, suggesting that the multiple functions performed by p53 in higher organisms may have been acquired later.

Several genes associated with various inherited diseases in humans are important for genome stability. Patients with Bloom's syndrome have an increase in sister chromatid exchange and a higher incidence of cancer due to mutation of the BLM gene (Ellis et al. 1995). A homolog of this RecQ helicase is also found in C. elegans (Table 1). ATR/X syndrome is characterized by X-linked mental retardation and $\alpha$-thalassemia (Gibbons et al. 1995). XNP/ATR-X is a putative DNA helicase involved in recombination and repair. The $C$. elegans homolog, xnp-1, contains the seven characteristic domains of this family of proteins (Villard et al. 1999). Analysis of C. elegans mutants of these homologs may provide greater insight into the regulation of genome stability.

Although homologs of many of the yeast and mammalian DNA repair and genome stability maintenance genes can be found in C. elegans, little is known about the role they have in DNA-damage-induced apoptosis. Thus, using recent powerful advances in reverse genetic technology in C. elegans, it is possible to quickly examine animals deficient for each of these genes. This should provide researchers with the tools to determine how the checkpoint controls communicate with the apoptotic machinery.

\section{CONCLUSIONS}

It has become evident from observations in human cancers and in mouse models that tumorigenesis is a process in which a cell acquires a growth advantage by multiple genetic changes (Hanahan and Weinberg 2000). These changes are not limited to mutations that lead to increased rates of proliferation but also that result in decreased rates of cell death. The importance of apoptosis in tumorigenesis was revealed with the discovery of up-regulation of the $\mathrm{Bcl}-2$ oncogene via chromosomal translocation in follicular lymphoma (Tsujimoto et al. 1984; Bakhshi et al. 1985). Since then, other regulators of apoptosis such as p53, Bax, and members of the death receptor pathways have been found to be mutated or have altered expression in several tumors (Arai et al. 1998; Beltinger et al. 1998; Yagi et al. 1998). For example, mutations in p53 are found in more than $50 \%$ of all cancers, and Bcl-2 is altered in more than $85 \%$ of patients afflicted with follicular lymphoma (Agarwal et al. 1998). Recently, it was discovered that a small fraction of patients with Li-Fraumeni syndrome have germ line mutations in the $h C H K 2$ gene, rather than in p53 (Bell et al. 1999). Thus, defects in the checkpoint pathway may lead to cancer. Radiation therapy is still a popular and successful form of treatment for several malignancies. Yet little is known about the molecular mechanisms of how tumor cells die and how some develop resistance. In particular, how DNA damage induces cell death is not well understood beyond the involvement of ATM and p53 (Morgan and Kastan 1997). Furthermore, it has become apparent that p53-independent pathways exist that can mediate DNA-damage-induced apoptosis (Evan and Littlewood 1998). Defects in the ability of cells to die when the DNA damage is extensive provide two growth advantages with a single hit on the road to cancer. The first is the ability of the cell to evade apoptosis. The second, and perhaps more significant, is survival of a cell with a mutated and possibly unstable genome. This is crucial because the multiple mutations present in a tumor are unlikely to occur within a lifetime due to the meticulous nature of DNA repair (Hanahan and Weinberg 2000). However, cancers are quite common. Therefore, an unprotected genome is the only way these mutations can accumulate. Recently, it has been proposed that cancer research will evolve into a logical science that, despite the many layers of complexity, will be understood in terms of basic principles (Hanahan and Weinberg 2000). This review aimed at convincing the reader that $C$. elegans provides a very powerful genetic tool to help define at least two of these principles: (1) How a cell determines whether to live or die in response to genotoxic stress and (2) how a cell becomes insensitive to this stress.

\section{REFERENCES}

Agarwal M.L., Taylor W.R., Chernov M.V., Chernova O.B., and Stark G.R. 1998. The p53 network. J. Biol. Chem. 273: 1.

Ahmed S. and Hodgkin J. 2000. MRT-2 checkpoint protein is required for germline immortality and telomere replication in C. elegans. Nature 403159.

Antonsson B., Conti F., Ciavatta A., Montessuit S., Lewis S., Martinou I., Bernasconi L., Bernard A., Mermod J.J., Mazzei G., Maundrell K., Gambale F., Sadoul R., and Martinou J.C. 1997. Inhibition of Bax channel-forming activity by Bcl-2. Science 277: 370.

Aoki H., Sato S., Takanami T., Ishihara T., Katsura I., Takahashi H., and Higashitani A. 2000. Characterization of Ce-atl1, an ATM-like gene from Caenorhabditis elegans. Mol. Gen. Genet. 264: 119.

Arai T., Akiyama Y., Okabe S., Saito K., Iwai T., and Yuasa Y. 1998. Genomic organization and mutation analyses of the DR5/TRAIL receptor 2 gene in colorectal carcinomas. Cancer Lett. 133: 197.

Bakhshi A., Jensen J.P., Goldman P., Wright J.J., McBride O.W., Epstein A.L., and Korsmeyer S.J. 1985. Cloning the chromosomal breakpoint of $\mathrm{t}(14 ; 18)$ human lymphomas: Clustering around $\mathrm{JH}$ on chromosome 14 and near a transcriptional unit on 18. Cell 41: 899.

Bell D.W., Varley J.M., Szydlo T.E., Kang D.H., Wahrer D.C., Shannon K.E., Lubratovich M., Verselis S.J., Isselbacher K.J., Fraumeni J.F., Birch J.M., Li F.P., Garber J.E., and Haber D.A. 1999. Heterozygous germ line $h C H K 2$ mutations in Li-Fraumeni syndrome. Science 286: 2528.

Beltinger C., Kurz E., Bohler T., Schrappe M., Ludwig W.D., and Debatin K.M. 1998. CD95 (APO-1/Fas) mutations in childhood T-lineage acute lymphoblastic leukemia. Blood 91: 3943 . 
Boxem M., Srinivasan D.G., and van den Heuvel S. 1999. The Caenorhabditis elegans gene $n c c-1$ encodes a $c d c 2$-related kinase required for $\mathrm{M}$ phase in meiotic and mitotic cell divisions, but not for S phase. Development 126: 2227.

Chen F., Hersh B.M., Conradt B., Zhou Z., Riemer D., Gruenbaum Y., and Horvitz H.R. 2000. Translocation of C. elegans CED-4 to nuclear membranes during programmed cell death. Science 287: 1485.

Chinnaiyan A.M., O'Rourke K., Lane B.R., and Dixit V.M. 1997. Interaction of CED-4 with CED-3 and CED-9: A molecular framework for cell death. Science 275: 1122

Clarke A.R., Purdie C.A., Harrison D.J., Morris R.G., Bird C.C., Hooper M.L., and Wyllie A.H. 1993. Thymocyte apoptosis induced by p53-dependent and independent pathways. $\mathrm{Na}$ ture 362: 849 .

Conradt B. and Horvitz H.R. 1998. The C. elegans protein EGL1 is required for programmed cell death and interacts with the Bcl-2-like protein CED-9. Cell 93: 519.

Dean F.B., Lian L., and O'Donnell M. 1998. cDNA cloning and gene mapping of human homologs for Schizosaccharomyces pombe rad17, radl, and hus 1 and cloning of homologs from mouse, Caenorhabditis elegans, and Drosophila melanogaster. Genomics 54: 424.

del Peso L., Gonzalez V.M., Inohara N., Ellis R.E., and Nunez G. 2000. Disruption of the CED-9.CED-4 complex by EGL1 is a critical step for programmed cell death in Caenorhabditis elegans. J. Biol. Chem. 275: 27205.

Edwards R.J., Bentley N.J., and Carr A.M. 1999. A Rad3-Rad26 complex responds to DNA damage independently of other checkpoint proteins. Nat. Cell Biol. 1: 393.

Ellis H.M. and Horvitz H.R. 1986. Genetic control of programmed cell death in the nematode $C$. elegans. Cell 44: 817.

Ellis N.A., Groden J., Ye T.Z., Straughen J., Lennon D.J., Ciocci S., Proytcheva M., and German, J. 1995. The Bloom's syndrome gene product is homologous to RecQ helicases. Cell 83: 655 .

Enoch T. and Norbury C. 1995. Cellular responses to DNA damage: Cell-cycle checkpoints, apoptosis and the roles of p53 and ATM. Trends Biochem. Sci. 20: 426.

Evan G. and Littlewood T. 1998. A matter of life and cell death. Science 281: 1317.

Fraser A. and James C. 1998. Fermenting debate: Do yeast undergo apoptosis? Trends Cell Biol. 8: 219.

Gartner A., Milstein S., Ahmed S., Hodgkin J., and Hengartner M.O. 2000. A conserved checkpoint pathway mediates DNA damage-induced apoptosis and cell cycle arrest in C. elegans. Mol. Cell 5: 435.

Gibbons R.J., Picketts D.J., Villard L., and Higgs D.R. 1995. Mutations in a putative global transcriptional regulator cause $\mathrm{X}$-linked mental retardation with alpha-thalassemia (ATR-X syndrome). Cell 80: 837.

Gumienny T.L., Lambie E., Hartwieg E., Horvitz H.R., and Hengartner M.O. 1999. Genetic control of programmed cell death in the Caenorhabditis elegans hermaphrodite germline. Development 126: 1011.

Hanahan D. and Weinberg R.A. 2000. The hallmarks of cancer. Cell 100: 57.

Hengartner M.O. and Horvitz H.R. 1994. C. elegans cell survival gene ced-9 encodes a functional homolog of the mammalian proto-oncogene $b c l-2$. Cell 76: 665 .

Hengartner M.O., Ellis R.E., and Horvitz H.R. 1992. Caenorhabditis elegans gene ced-9 protects cells from programmed cell death. Nature 356: 494.

Horvitz H.R. 1999. Genetic control of programmed cell death in the nematode Caenorhabditis elegans. Cancer Res. 59: 1701s.

Ketting R.F., Haverkamp T.H., van Luenen H.G., and Plasterk R.H. 1999. Mut-7 of C. elegans, required for transposon silencing and RNA interference, is a homolog of Werner syndrome helicase and RNaseD. Cell 99: 133.

Kiefer M.C., Brauer M.J., Powers V.C., Wu J.J., Umansky S.R., Tomei L.D., and Barr P.J. 1995. Modulation of apoptosis by the widely distributed Bcl-2 homologue Bak. Nature 374: 736.

Kimble J.E. and White J.G. 1981. On the control of germ cell de- velopment in Caenorhabditis elegans. Dev. Biol. 81: 208.

Metzstein M.M., Stanfield G.M., and Horvitz H.R. 1998. Genetics of programmed cell death in C. elegans: Past, present and future. Trends Genet. 14: 410.

Morgan S.E. and Kastan M.B. 1997. p53 and ATM: Cell cycle, cell death, and cancer. Adv. Cancer Res. 71: 1.

Nurse P. 1997. Checkpoint pathways come of age. Cell 91: 865 . 2000. A long twentieth century of the cell cycle and beyond. Cell 100: 71 .

O'Connell M.J., Walworth N.C., and Carr A.M. 2000. The G2phase DNA-damage checkpoint. Trends Cell Biol. 10: 296.

Oltvai Z.N., Milliman C.L., and Korsmeyer S.J. 1993. Bcl-2 heterodimerizes in vivo with a conserved homolog, Bax, that accelerates programmed cell death. Cell 74: 609.

Orr-Weaver T.L. and Weinberg R.A. 1998. A checkpoint on the road to cancer. Nature 392: 223.

Rhind N. and Russell P. 1998. Mitotic DNA damage and replication checkpoints in yeast. Curr. Opin. Cell Biol. 10: 749.

Rich T, Allen R. L., and Wyllie A.H. 2000. Defying death after DNA damage. Nature 407: 777.

Riddle D.L., Blumenthal T., Meyer B.J., and Priess J.R., Eds. 1997. C. elegans II. Cold Spring Harbor Laboratory Press, Cold Spring Harbor, New York.

Roeder G.S. 1997. Meiotic chromosomes: It takes two to tango. Genes Dev. 11: 2600.

Saka Y., Esashi F., Matsusaka T., Mochida S., and Yanagida M. 1997. Damage and replication checkpoint control in fission yeast is ensured by interactions of $\mathrm{Crb} 2$, a protein with BRCT motif, with Cut5 and Chk1. Genes Dev. 11: 3387.

Schedl T. 1997. Developmental genetics of the germ line. In C. elegans $I I$ (ed. D.L. Riddle et al.), p. 241. Cold Spring Harbor Laboratory Press, Cold Spring Harbor, New York.

Srinivasula S.M., Ahmad M., Fernandes-Alnemri T., and Alnemri E.S. 1998. Autoactivation of procaspase-9 by Apaf-1mediated oligomerization. Mol. Cell 1: 949.

Strasser A., Harris A.W., Jacks T., and Cory S. 1994. DNA damage can induce apoptosis in proliferating lymphoid cells via p53-independent mechanisms inhibitable by Bcl-2. Cell 79: 329.

Takanami T., Sato, S., Ishihara T., Katsura I., Takahashi H., and Higashitani A. 1998. Characterization of a Caenorhabditis elegans recA-like gene Ce-rdh-1 involved in meiotic recombination. DNA Res. 5: 373.

Tsujimoto Y., Finger L.R., Yunis J., Nowell P.C., and Croce C.M. 1984. Cloning of the chromosome breakpoint of neoplastic B cells with the $t(14 ; 18)$ chromosome translocation. Science 226: 1097.

Villard L., Fontes M., and Ewbank J.J. 1999. Characterization of xnp-1, a Caenorhabditis elegans gene similar to the human XNP/ATR-X gene. Gene 236: 13.

Weinert T. 1998. DNA damage checkpoints update: Getting molecular. Curr. Opin. Genet. Dev. 8: 185.

Wood W.B., Ed. 1988. The Nematode Caenorhabditis elegans. Cold Spring Harbor Laboratory Press, Cold Spring Harbor, New York.

Xue D., Shaham S., and Horvitz H.R. 1996. The Caenorhabditis elegans cell-death protein CED-3 is a cysteine protease with substrate specificities similar to those of the human CPP32 protease. Genes Dev. 10: 1073.

Yagi O.K., Akiyama Y., Nomizu T., Iwama T., Endo M., and Yuasa Y. 1998. Proapoptotic gene BAX is frequently mutated in hereditary nonpolyposis colorectal cancers but not in adenomas. Gastroenterology 114: 268.

Yang X., Chang H.Y., and Baltimore D. 1998. Essential role of CED-4 oligomerization in CED-3 activation and apoptosis. Science 281: 1355.

Yuan J., Shaham S., Ledoux S., Ellis H.M., and Horvitz H.R. 1993. The $C$. elegans cell death gene ced-3 encodes a protein similar to mammalian interleukin-1 beta-converting enzyme. Cell 75: 641.

Zou H., Henzel W.J., Liu X., Lutschg A., and Wang X. 1997. Apaf-1, a human protein homologous to C. elegans CED-4, participates in cytochrome c-dependent activation of caspase3. Cell 90: 405 . 
